\title{
Procesamiento cerámico de $\beta$-TCP para la fabricación de piezas implantables
}

\author{
J. FRANCO' ${ }^{1}$, A. SOUTO', P. REY', F. GUITIÁN' ${ }^{1}$, A. MARTíNEZ ÍNSUA². \\ 'Instituto de Cerámica de Galicia. Avda. Mestre Mateo s/n. 15706 Santiago de Compostela. \\ ${ }^{2}$ Facultad de Medicina y Odontología- Universidad de Santiago de Compostela. Entrerríos s/n. 15782 Santiago de Compostela.
}

\begin{abstract}
El trabajo describe la puesta a punto de un método de obtención de grandes cantidades de fosfato tricálcico $(\beta$-TCP), por precipitación a partir de disoluciones de sales de calcio y de fosfatos. Para ello se estudia la influencia de los parámetros de operación tales como concentración de reactivos, velocidad de adición, $\mathrm{pH}$ de precipitación y tiempo de envejecimiento del precipitado. El procedimiento, que es escalable a nivel industrial, permite obtener $\beta$-TCP de elevada pureza, que cumple ASTM F1088-87. Con el material obtenido se procesan barras implantables por prensado, colado, gel-casting e inyección, que se caracterizan detalladamente, y posteriormente se implantan en la tibia de perros Beagle. El estudio histológico en lámina delgada de los implantes, tras períodos de implantación de 2, 7 y 14 meses, permite evaluar la excelente biocompatibilidad del material y su carácter reabsorbible.
\end{abstract}

Palabras clave: beta-TCP, sintesis, moldeo por gelificación, moldeo por inyección.

\section{Ceramic processing of beta-TCP for producing implantable shapes.}

This work describes a method for obtaining large-scale productions of $\beta$-TCP by mass-precipitation from calcium and phosphate solutions. The setting of the synthesis conditions was made by studying operational parameters like the concentrations of the reagents, the speed of the mixing of the reagents, $\mathrm{pH}$ of precipitation and ageing of the precipitate. This synthesis procedure allows obtaining high purity $\beta$-TCP under ASTM F1088-87. Starting from synthesized $\beta$-TCP were made rods for implantation by die pressing, slip casting, gel casting and low pressure injection moulding. These rods were well characterized and implanted in Beagle dogs. Thin film histological results for 2, 7, and 14 months of implantation period, shown a good biocompatibility for the material and its resorbable behaviour.

Keywords: beta-TCP, synthesis, gelcasting, LPIM.

\section{INTRODUCCIÓN}

Los primeros ensayos del uso de fosfato tricálcico como sustituto óseo fueron realizados por Albee y Morrison (1) en 1920, aunque la utilización clínica de los fosfatos cálcicos no se generalizó hasta 1970 (2). Hoy en día, la gran biocompatibilidad de estos compuestos y su utilidad para tratar distintos tipos de defectos óseos es indiscutible y su uso se está generalizando en todos los países $(3,4)$.

De entre todos los fosfatos cálcicos los más estudiados y utilizados son el $\beta$ fosfato tricálcico $\left(\beta-\mathrm{TCP}, \beta-\mathrm{Ca}_{3}\left(\mathrm{PO}_{4}\right)_{2}\right)$ y el hidroxiapatito ( $\left.\mathrm{HA}, \mathrm{Ca}_{10}\left(\mathrm{PO}_{4}\right)_{6}(\mathrm{OH})_{2}\right)$. Ambos son ortofosfatos cálcicos, pero a pesar de tener una composición química muy similar (Tabla I) su comportamiento en las condiciones del medio fisiológico es muy diferente. En los diagramas construidos a partir del producto de solubilidad $(5,6)$ (Figura 1) se observa que el $\beta$-TCP es más soluble que el HA a todos los $\mathrm{pHs}$, hecho que se refleja en el medio fisiológico por la estabilidad del HA frente a la relativa solubilidad del $\beta$-TCP, que es reabsorbido gradualmente.

Esta estabilidad a largo plazo del HA en las condiciones de $\mathrm{pH}$ y temperatura del medio fisiológico y su excelente bioactividad cuando se emplea como sustituto óseo $(7,8)$ lo han convertido en el material biocerámico de referencia. Sin embargo, para determinadas aplicaciones, la baja reabsorción que presentan los implantes de HA representa un problema, ya que dificulta la remodelación ósea por procesos de disolución precipitación (9). Como consecuencia, en los últimos años, se ha incrementado el uso de $\beta$-TCP como material para sustitución ósea, debido a su relativa solubilidad, sus propiedades osteoconductoras y a su gran biocompatibilidad $(10,11,12)$. La disolución de $\beta$-TCP en medio fisiológico fuerza la precipitación "in situ" de un carbohidroxiapatito de baja cristalinidad (13), que con el tiempo se va transformando en un HA cada vez mejor cristalizado conforme madura el hueso neo-formado, alcanzándose finalmente una relación $\mathrm{Ca} / \mathrm{P} \sim 1,67$ muy próxima a la del HA estequiométrico.

La mayoría de las síntesis descritas para $\beta$-TCP sólo permiten obtener pequeñas cantidades de este compuesto, mediante reacciones de precipitación en disoluciones diluidas, por procedimientos sol-gel, o por reacciones de alta temperatura.

TABLA I. COMPOSICIÓN QUÍMICA REFERIDA AL PORCENTAJE EN PESO DE CADA ELEMENTO PARA HA Y B-TCP.

\begin{tabular}{|c|c|c|c|c|}
\hline Compuesto & $\% \mathrm{Ca}$ & $\% \mathrm{P}$ & $\% \mathrm{O}$ & $\% \mathrm{H}$ \\
\hline$\beta$-TCP & 38,76 & 19,97 & 41,26 & 0 \\
\hline $\mathrm{HA}$ & 39,89 & 18,50 & 41,41 & 0,20 \\
\hline
\end{tabular}




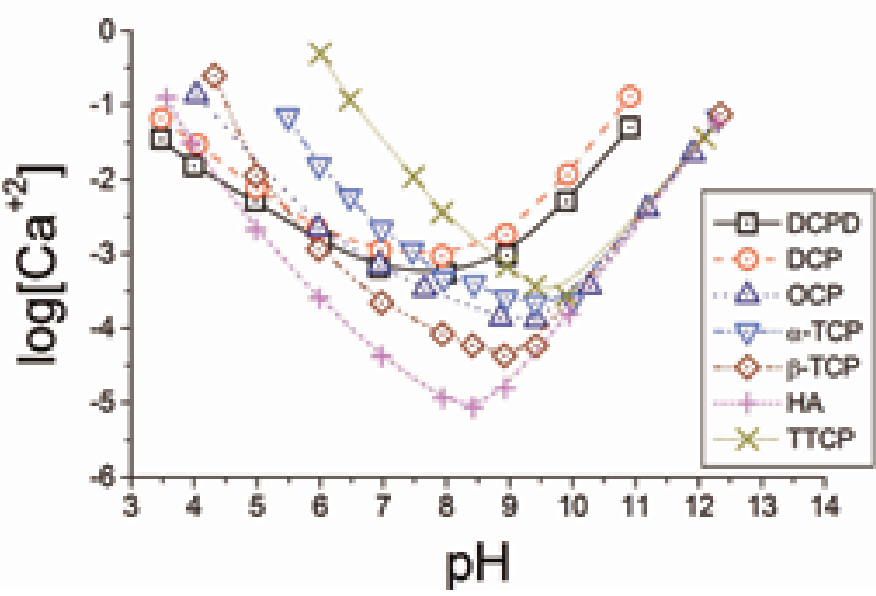

Fig. 1.- Diagrama de solubilidad. Las líneas representan los límites de solubilidad para diferentes ortofosfatos cálcicos representadas frente al pH y al logaritmo de la concentración de calcio Figura 2

El objetivo fundamental de este trabajo ha sido la puesta a punto de un método para la fabricación de $\beta$-TCP de alta pureza en grandes cantidades, que cumpla con la norma de pureza ASTM F 1088-87 para su uso en procedimientos quirúrgicos como sustituto óseo (pureza por DRX $>95 \%$ y límites para concentración de metales pesados). Este procedimiento debe ser además susceptible de un fácil escalado industrial.

El procedimiento empleado es una ruta por vía húmeda, en la que se precipita un precursor amorfo, que tras un tratamiento térmico adecuado cristaliza en forma de $\beta$-TCP. Partiendo del material sintetizado, se compararon las propiedades exhibidas por piezas de $\beta$-TCP preparadas siguiendo diferentes rutas de procesamiento. También se estudió el comportamiento 'in vivo' de implantes de $\beta$-TCP en perros Beagle de 2 a 14 meses.

\section{EXPERIMENTAL}

\subsection{Síntesis de $\beta$-TCP}

El método empleado consiste en la precipitación masiva a partir de disoluciones de calcio y fosfatos de un precursor con relación $\mathrm{Ca} / \mathrm{P}=1,5$, de acuerdo con la reacción:

$$
3 \mathrm{Ca}^{2+}{ }_{(\mathrm{aq})}+2 \mathrm{PO}_{4}^{3-}{ }_{(\mathrm{aq})} \rightarrow \mathrm{Ca}_{3}\left(\mathrm{PO}_{4}\right)_{2} \cdot \mathrm{xH}_{2} \mathrm{O} \downarrow_{(\mathrm{s})}
$$

En la figura 2 se muestra un esquema del proceso seguido. Para preparar las disoluciones de calcio se empleó nitrato cálcico tetrahidratado $\left(\mathrm{Ca}\left(\mathrm{NO}_{3}\right)_{2} \cdot 4 \mathrm{H}_{2} \mathrm{O}\right.$ Merck, P.A., pureza 99\%), y en la preparación de las disoluciones de fosfatos se empleó una disolución de ácido ortofosfórico $\left(\mathrm{H}_{3} \mathrm{PO}_{4^{\prime}}\right.$ Panreac, P.A. 85\% en peso). El volumen para cada disolución fue de 5l, y el pH de las disoluciones se ajustó añadiendo disoluciones concentradas de amoniaco $\left(\mathrm{NH}_{4} \mathrm{OH}\right.$, Merck, P.A., 32\% en peso). El pH de las disoluciones se controló con un medidor de $\mathrm{pH}$ provisto de una microsonda Pt100 que mide la temperatura (Metrohm-704 pHmeter). No se trabajó con un valor de $\mathrm{pH}$ superior a 10,5 para evitar la formación de fosfato amónico en las disoluciones de fosfatos, lo que dificultaría el proceso de síntesis (14). Para calibrar el medidor se emplearon disoluciones reguladoras (Riedel de Häen). Las concentraciones estudiadas en las disoluciones de calcio

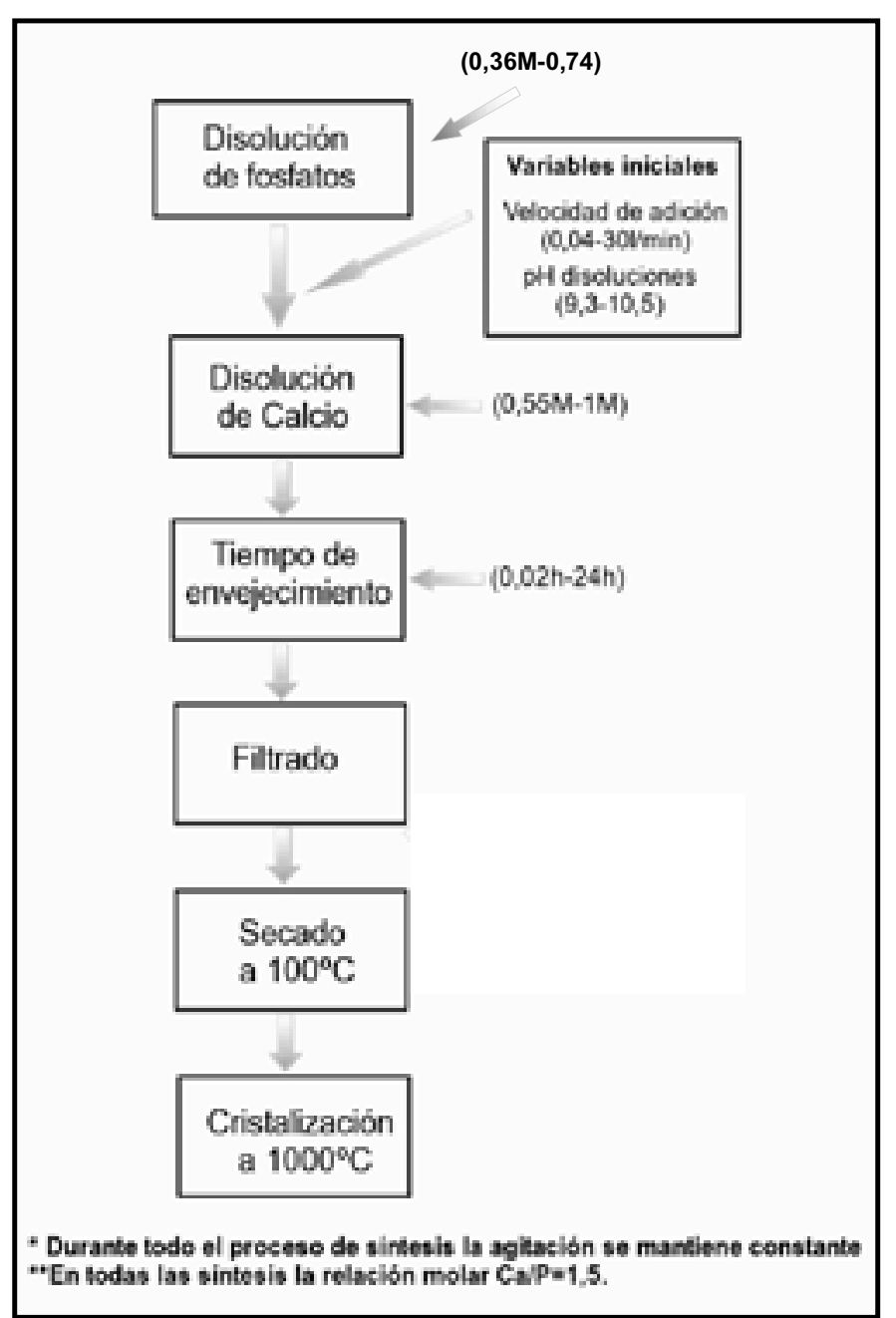

Fig. 2.- Esquema del proceso de síntesis para obtener $\beta$-TCP, donde se detallan las condiciones utilizadas y variables estudiadas.

fueron $0,55 \mathrm{M}, 0,7 \mathrm{M}, 0,9 \mathrm{M}, 1 \mathrm{M}$ y $1,1 \mathrm{M}$, usándose para el fósforo las concentraciones correspondientes de $0,37 \mathrm{M}, 0,47 \mathrm{M}, 0,6 \mathrm{M}$, $0,67 \mathrm{M}$ y $0,74 \mathrm{M}$, de modo que en todo momento se mantuvo una relación molar $\mathrm{Ca} / \mathrm{P}=1,5$.

La disolución de fosfato se añadió sobre la de calcio con velocidades de adición de 0,04 1/min, 0,08 1/min, 0,5 $1 / \min , 5 \mathrm{l} / \mathrm{min}, 15 \mathrm{l} / \mathrm{min}$ y $30 \mathrm{l} / \mathrm{min}$. Concluida la adición de la disolución se mantuvo la agitación por un espacio de tiempo denominado tiempo de envejecimiento. Los tiempos de envejecimiento empleados fueron $0,02 h, 0,04 h, 0,5 h, 1 h, y$ 24h. Pasado este tiempo se filtró para obtener un gel. Las aguas madres se analizaron mediante espectroscopia de emisión de plasma (ICP-OES, Varian Liberty 200). En ningún caso se detectaron concentraciones de calcio y fósforo superiores a $5 \mathrm{ppm}$, lo que demuestra que, prácticamente, todo el calcio y el fósforo contenido en las disoluciones iniciales se encuentran en el precipitado, manteniendo la relación $\mathrm{Ca} / \mathrm{P}=1,5$ presente en las disoluciones de partida.

Después de filtrados, los geles obtenidos se secaron en una estufa a $110^{\circ} \mathrm{C}$ por espacio de $24 \mathrm{~h}$, tras el cual se introdujeron en un horno a $1000^{\circ} \mathrm{C}$ durante $2 \mathrm{~h}$ para cristalizar $\beta$-TCP. El producto obtenido se molió en un molino excéntrico de ágata (Retsch). El material se tamizó por una luz de malla con $63 \mu \mathrm{m}$ (Restch) y se obtuvieron polvos cuya composición mineralógica se comprobó por difracción de rayos $\mathrm{X}$ (DRX) 
(Siemens D-5000, Cu $\mathrm{K}_{\alpha 1} \lambda=1,54 \AA$ a $30 \mathrm{~mA}$ y $40 \mathrm{kV}$ con el software de análisis AXS 2.3 de Bruker). Para el análisis cuantitativo se prepararon mezclas de HA y $\beta$-TCP (picos $[2$ 1 1] y [0 2 10] respectivamente) y se construyó una recta de calibrado (15) barriendo en el intervalo de $2 \theta$ de $30,4^{\circ}$ a $32,1^{\circ}$ con un incremento de $0,002^{\circ}$ y 3 s de acumulación, consiguiendo detectar concentraciones de HA hasta el $1 \%$. Igualmente se analizó el intervalo de $2 \theta$ correspondiente de $20^{\circ}$ a $40^{\circ}$ con un incremento de $0,05^{\circ}$ y $2 \mathrm{~s}$ de acumulación para garantizar la ausencia de otros fosfatos cálcicos. Para determinar el tamaño medio de partícula de los polvos se empleó una técnica de absorción de rayos X (Sedigraph 5100).

\subsection{Procesamiento de piezas.}

Para el procesamiento cerámico de piezas de $\beta$-TCP se utilizaron técnicas convencionales como son el colado y el prensado, y técnicas no convencionales como el colado con gelificación ( gel-casting) en caliente de masas plásticas, y moldeo por inyección a baja presión de pastas fluidas seguido de gelificación en frío. Se prepararon piezas cilíndricas por cada una de las técnicas, y se estudiaron sus propiedades físicas (\% porosidad, \% contracción, densidad aparente, resistencia a compresión) así como sus microestructuras.

Las piezas por colado se prepararon a partir de suspensiones de $\beta$-TCP con un $80 \%$ de contenido en sólidos, con un $0,2 \%$ de Reotán-L como agente dispersante, (Aditivos Cerámicos Lamberti S.L.) en moldes de escayola. Se ajustó la viscosidad de la suspensión empleada a $1200 \mathrm{MPa} \cdot \mathrm{s}$. Para medir la viscosidad se empleó un viscosímetro rotacional (Viscolog DRV-400). Tras desmoldar las piezas se secaron en la estufa por espacio de $24 \mathrm{~h}$ a $37^{\circ} \mathrm{C}$. Una vez secas se introdujeron en un horno y se procesaron térmicamente a $1100^{\circ} \mathrm{C}$ durante dos horas con velocidades de subida y de bajada de $5^{\circ} / \mathrm{min}$.

Las piezas preparadas por prensado se obtuvieron en una prensa hidráulica manual (Graseby, 15ton), empleando un molde cilíndrico articulado construido en acero inoxidable provisto de un pistón y una toma de vacío. Los polvos de $\beta$-TCP se mezclaron con un $2 \%$ de celulosa microcristalina (Merck) para facilitar la compactación y minimizar las deslaminaciones. Las piezas se prensaron a 74MPa de presión efectiva. La sinterización de las piezas se realizó de igual modo que para las piezas preparadas por colado.

Para la preparación de piezas por gelificación en caliente se empleó metil celulosa (Sigma-Aldrich) como agente gelificante. Las masas plásticas se prepararon mezclando los polvos de $\beta$-TCP con la metil celulosa ( Mezcladora Turbula, $\mathrm{WAB}$ ), por espacio de $2 \mathrm{~h}$. A continuación se añadió la cantidad de agua necesaria para alcanzar un $71 \%$ en peso de $\beta$-TCP y se sometió el conjunto a un amasado intensivo para minimizar la presencia de agregados. El contenido final en metil celulosa fue de un $3,3 \%$. La viscosidad de las pastas a $37^{\circ} \mathrm{C}$ fue de 8000Pa.s (Reómetro AR2000 de la casa TA Instruments). La pasta se introdujo en el molde y se gelificó durante 15 minutos a $105^{\circ} \mathrm{C}$. Después de desmoldar, las piezas se secaron en una estufa a $37^{\circ} \mathrm{C}$ durante $24 \mathrm{~h}$. El tratamiento térmico se realizó con una subida de temperatura inicialmente muy lenta $\left(1^{\circ} \mathrm{C} / \mathrm{min}\right)$, para no comprometer la integridad de las piezas debido a la salida de gases procedentes de la pirólisis de la metil celulosa (16). A partir de $500^{\circ} \mathrm{C}$ la velocidad de subida fue de $5^{\circ} \mathrm{C} / \mathrm{min}$ hasta $1100^{\circ} \mathrm{C}$, seguida de una etapa de permanencia de $2 \mathrm{~h}$ para bajar luego a $5^{\circ} \mathrm{C} / \mathrm{min}$ hasta temperatura ambiente.

En el caso del moldeo por inyección se empleó una máquina de moldeo por inyección a baja presión semiautomática (Low
Pressure Injection Moulding, LPIM) Pelcorp MIGL-33C. Como agente de gelificación se utilizó Agar-agar (Hipanagar). Las pastas fluidas se prepararon por mezclado en caliente $\left(75^{\circ} \mathrm{C}\right)$ de la disolución de agar-agar en agua con el polvo de TCP, formando una suspensión. Todo el proceso se realiza en el interior de la cámara de mezcla de la máquina de inyección. La viscosidad de la suspensión a $75^{\circ} \mathrm{C}$ se midió con un viscosímetro rotacional termostatado (Viscolog DRV-400). El valor de la viscosidad fue de 50Pa·s. La composición final de la pasta utilizada fue $71 \%$ de contenido en sólidos de $\beta$-TCP y un 1,5\% de Agar-agar y un 27,5\% de agua. La gelificación se produce al enfriar la pasta dentro del molde refrigerado. Una vez desmoldadas, las piezas se secaron y procesaron térmicamente del mismo modo que las piezas preparadas con metil celulosa. En ningún caso se superaron $\operatorname{los} 1100^{\circ} \mathrm{C}$ de temperatura para evitar la transformación polimórfica entre $\alpha$ y $\beta$-TCP en las piezas obtenidas.

Para la realización de ensayos mecánicos de resistencia a compresión se empleó una máquina de ensayos universal (Suzpecar) según procedimientos anteriormente descritos (17).

\subsection{Ensayos 'in vivo'.}

Se prepararon 3 series de 4 cilindros de $\beta$-TCP de $3 \mathrm{~mm}$ de diámetro y $6 \mathrm{~mm}$ de longitud, utilizando el procedimiento descrito de gelificación en caliente. Estas piezas fueron implantadas en la meseta tibial de perros Beagle, que se sacrificaron al cabo de 2, 7 y 14 meses. En cada perro se implantaron 4 cilindros y se utilizó un perro por cada tiempo evaluado. Los perros empleados en este estudio han sido atendidos siguiendo las buenas prácticas de laboratorio según Real Decreto 223/1988, de 14 de marzo, sobre la protección de animales utilizados en experimentación y otros fines científicos (BOE de 18 de marzo de 1988). Tras sacrificar los animales se extrajeron las tibias y se introdujeron en formol al 10\% tamponado ( $\mathrm{pH} 7,4)$. Los huesos se deshidrataron por intercambio de alcoholes y se incluyeron en un bloque de resina fotopolimerizable (Technovit 7200). Para poder evaluar la interfase hueso-implante se prepararon láminas delgadas sin descalcificar con espesores de entre $10 \mu \mathrm{m}$ y $15 \mu \mathrm{m}$ (18), y se tiñeron empleando Hematoxilina de Harris (Merck) y tinción tricrómica según la modificación de Wheatley (Newcomer supply). Las láminas se cubrieron con bálsamo de Canadá (Fluka) y se examinaron con un microscopio óptico de luz transmitida (Nikon OPTIPHOT2-PQL) equipado con un sistema de fotografía digital (Olympus DP-12 con 3,3 Mpixels)

\section{RESULTADOS Y DISCUSIÓN}

\subsection{Síntesis de $\beta$-TCP.}

Se ha estudiado la influencia de cada una de las variables de procesamiento sobre la pureza del $\beta$-TCP (velocidad de adición de reactivos, tiempo de envejecimiento, $\mathrm{pH}$ de las disoluciones y concentración de los reactivos). En la tabla II se muestran las condiciones de síntesis que se mantuvieron fijas para el estudio de cada una de dichas variables. Un resumen de los resultados de este estudio se representa en la figura 3. Como puede verse, el incremento de la velocidad de adición de calcio sobre la de fosfatos supone un enriquecimiento en $\beta$-TCP de los productos obtenidos. Fijando velocidades 
TABLA II. CONDICIONES DE SÍNTESIS PARA CADA UNA DE LAS VARIABLES ESTUDIADAS.

\begin{tabular}{|c|c|c|c|c|}
\hline & \multicolumn{4}{|c|}{ Valores fijos frente a la variable estudiada } \\
\hline $\begin{array}{c}\text { Variable } \\
\text { estudiada }\end{array}$ & V. Adición & T. Envejec. & $\mathrm{pH}$ & $\begin{array}{c}\text { Concentr. } \\
\text { Ca. }\end{array}$ \\
\hline V. adición & - & $24 \mathrm{~h}$ & 9,3 & $0,55 \mathrm{M}$ \\
\hline T. Envejec. & $301 / \mathrm{min}$ & - & 9,3 & $0,55 \mathrm{M}$ \\
\hline $\mathrm{pH}$ & $301 / \mathrm{min}$ & $1 \mathrm{~min}$ & - & $0,55 \mathrm{M}$ \\
\hline $\begin{array}{c}\text { Concentr. } \\
\text { Ca }\end{array}$ & $301 / \mathrm{min}$ & $1 \mathrm{~min}$ & 10 & - \\
\hline
\end{tabular}

\section{Influencia de las variables en la pureza del $\beta$-tcp obtenido}
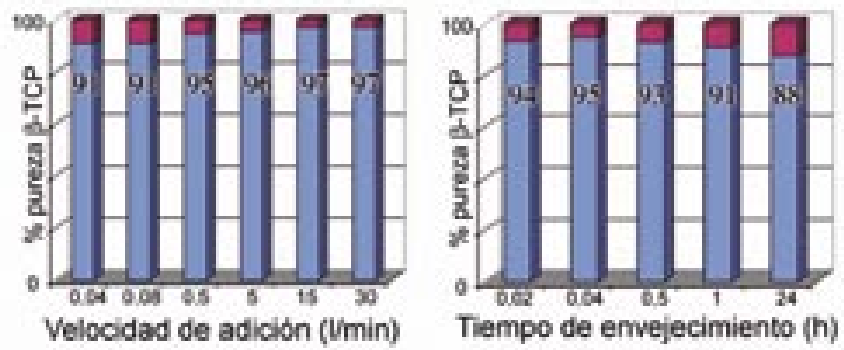

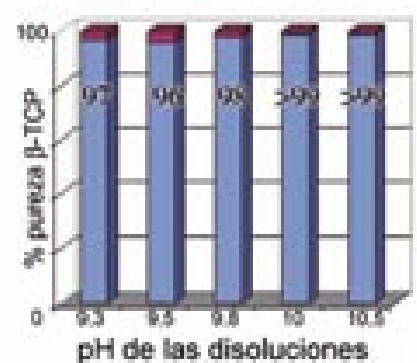

B-TCP

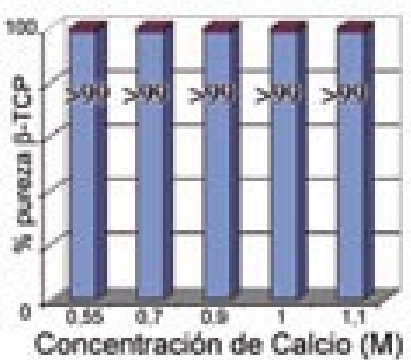

Etros fosfatos calcicos
Fig. 3.- Influencia de las variables de síntesis en la pureza del $\beta$-TCP obtenido. Se indica en cada columna el porcentaje de $\beta$-TCP obtenido para cada síntesis.

de adición altas, el aumento del tiempo de envejecimiento se traduce en la presencia de otros fosfatos, principalmente HA. Conservando alta la velocidad de adición $(30 \mathrm{l} / \mathrm{min})$ y un tiempo de envejecimiento de 1 minuto, se observa que el incremento en el valor del $\mathrm{pH}$ favorece la obtención de un $\beta$-TCP de mayor pureza, siendo indetectables por DRX la presencia de otros fosfatos de calcio a partir de $\mathrm{pH}$ 10. Con un tiempo de envejecimiento de 1 minuto, una velocidad de adición de 30 1/min y pH 10, la concentración de las disoluciones de los reactivos no afecta a la pureza del $\beta-\mathrm{TCP}$, obteniéndose en todos los casos un $\beta$-TCP con una pureza superior al $99 \%$. De acuerdo con estos resultados, las condiciones óptimas de síntesis son: una velocidad de adición de $30 \mathrm{l} / \mathrm{min}$, un tiempo de envejecimiento de 1 minuto, $\mathrm{pH}$ 10, y una concentración de calcio de 1,1M y 0,73M para la disolución de fosfatos. Por otra parte, el incremento de la velocidad de adición de los fosfatos supuso un tiempo de reacción menor que se tradujo en una mayor pureza del $\beta$-TCP obtenido.
Es conocido que, a los pHs de trabajo, el HA es el fosfato cálcico termodinámicamente más estable (7). Por ello, si el proceso de precipitación se lleva a cabo en condiciones termodinámicas próximas al equilibrio se favorece la formación de HA (largo tiempo de envejecimiento, velocidad de adición lenta, disoluciones diluidas), mientras que si las condiciones del proceso impiden o dificultan este equilibrio (tiempo de envejecimiento mínimo, alta velocidad de adición, disoluciones concentradas) se obtiene $\beta$-TCP de elevada pureza, de acuerdo con la estequiometría de la reacción $(\mathrm{Ca} /$ $P=1,5)$. En la figura $4 \mathrm{~A}$ se muestra la difracción de rayos $X$ de un polvo de $\beta$-TCP con una pureza superior al $99 \%$ calcinado a $1000^{\circ} \mathrm{C} 2 \mathrm{~h}$. El barrido lento del intervalo $2 \theta\left(30,4^{\circ}-32,1^{\circ}\right)$, no detecta la presencia de ningún otro fosfato cálcico $\left(\mathrm{Ca}_{2} \mathrm{P}_{2} \mathrm{O}_{7} \mathrm{y}\right.$ HA) Figura 4B. El rendimiento del proceso propuesto para sintetizar $\beta$-TCP es superior al $95 \%$ respecto a la cantidad de reactivos empleada.

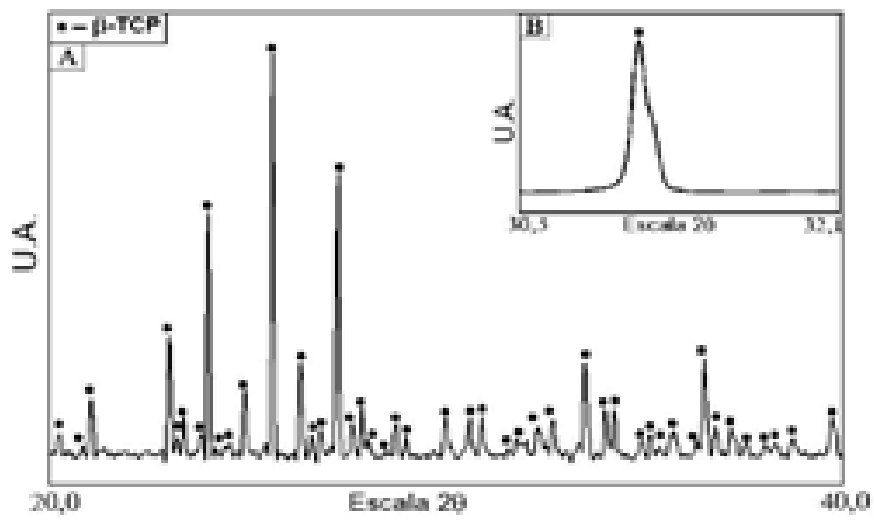

Fig. 4.- .A) Difractograma correspondiente a $\beta$-TCP de pureza $>99 \%$ obtenido después de permanecer $2 \mathrm{~h}$ a $1000^{\circ} \mathrm{C}$. B) Barrido lento entre $31,4^{\circ}$ y $32,1^{\circ}$ $2 \theta$ para comprobar la ausencia de otros fosfatos cálcicos. El pequeño hombro que aparece en el pico de difracción se debe a la radiación $\mathrm{K} \alpha{ }_{2}$ del $\mathrm{Cu}$. Nótese la ausencia de difracciones correspondientes a otros fosfatos.

\subsection{Procesamiento de piezas.}

En la tabla III se muestran las propiedades físicas y mecánicas de las piezas preparadas por las diferentes rutas de procesamiento y en la figura 5 se comparan sus microestructuras. Las mejores densidades se consiguieron en piezas procesadas por colado seguidas de las obtenidas por prensado. Las contracciones más elevadas las alcanzaron las piezas procesadas a partir de masas plásticas y pastas fluidas. Las mayores resistencias se registran en las piezas preparadas por prensado seguidas de las coladas. Es interesante destacar que las piezas coladas, a pesar de tener menor porosidad y mayor densidad aparente, resisten la mitad que las preparadas por prensado. Este comportamiento aparentemente anómalo se asocia a la presencia de grandes poros aislados de $40-50 \mu \mathrm{m}$, debidos a un desaireado insuficiente de las suspensiones.

\subsection{Ensayos 'in vivo'}

Desde el punto de vista histológico, el material sufre una serie de procesos de reabsorción-sustitución progresiva. 
TABLA III. PROPIEDADES DE LAS PIEZAS OBTENIDAS POR LAS DIFERENTES RUTAS DE PROCESAMIENTO UTILIZADAS.

\begin{tabular}{|c|c|c|c|c|}
\hline Procesamiento & $\%$ Contracc. & $\begin{array}{c}\text { D. Aparente } \\
\mathrm{g} / \mathrm{cm}^{3} .\end{array}$ & $\begin{array}{c}\% \\
\text { Porosidad }\end{array}$ & $\sigma_{\mathrm{c}}(\mathrm{MPa})$ \\
\hline Colado & 15,2 & 2,7 & 10,9 & 104,1 \\
\hline Prensado & 16,9 & 2,6 & 13,6 & 201,5 \\
\hline Gel-Casting & 17,6 & 2,2 & 29 & 67,2 \\
\hline LPIM & 19,9 & 2,2 & 28 & 70,3 \\
\hline
\end{tabular}

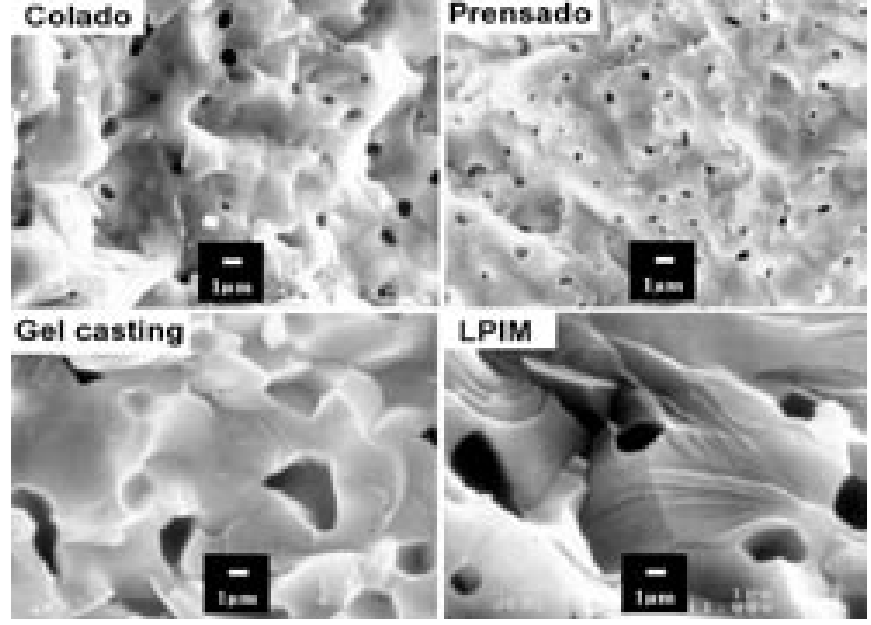

Fig. 5.- Imágenes SEM. Microestructura de fractura de las piezas procesadas por las diferentes técnicas empleadas.

La superficie del implante es colonizado en un primer momento por proteínas y células, y posteriormente por tejido fibrovascular con intensa actividad angiogénica y ribetes de células multinucleadas que proceden a la remoción del material. El progreso de esta colonización hacia el interior del implante depende fuertemente de la presencia en el material de poros interconectados con túneles internos. En una segunda fase la matriz proteica extracelular que embebe fragmentos del material se mineraliza, quedando englobado material proveniente del implante en su interior. Este material va siendo sustituido progresivamente por matriz extracelular típica.

En ninguna de las muestras evaluadas se ha producido la reabsorción completa al cabo de 14 meses, si bien parece que en el último periodo 7-14 meses la velocidad de reabsorción aumenta En la figura 6 se muestra la degradación del material implantado en imágenes reconstruidas a partir de varias fotografías, para muestras a 2, 7 y 14 meses. El círculo marca la dimensión original del material implantado y las líneas punteadas la interfase entre el hueso neo-formado y el material implantado.

Interfase hueso-implante. En un primer momento la superficie del implante es bastante estable frente al medio interno, lo que permite, tal y como se muestra en la figura 7 , una aposición del hueso neo-formado prácticamente directa sobre la superficie del implante (zona marcada con flechas). En el interior de una zona circular puede verse en el hueso neo-formado una inserción de una yema vascular sobre la superficie del material. En esta imagen también puede observarse como la orientación del hueso neo-formado sigue la dirección de la superficie del implante frente al crecimiento

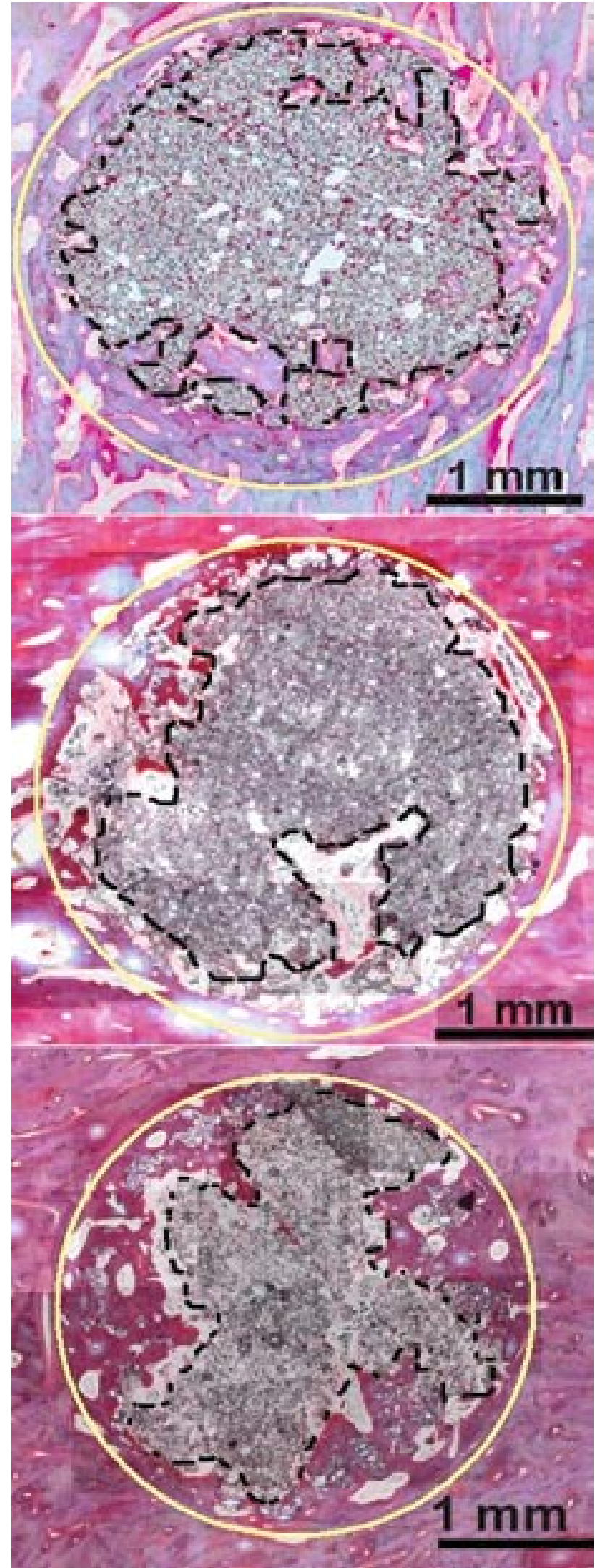

Fig. 6.- Imágenes reconstruidas cada una de ellas a partir de $38 \mathrm{mi}$ crofotógrafías ópticas de luz transmitida de la zona de implante de $\beta$-TCP. Arriba: 2 meses de implantación; en el medio, 7 meses de implantación; abajo 14 meses de implantación. Se delimita con un círculo amarillo el contorno original del implante. El espacio comprendido entre el círculo y las líneas punteadas negras corresponde al hueso neo-formado. 


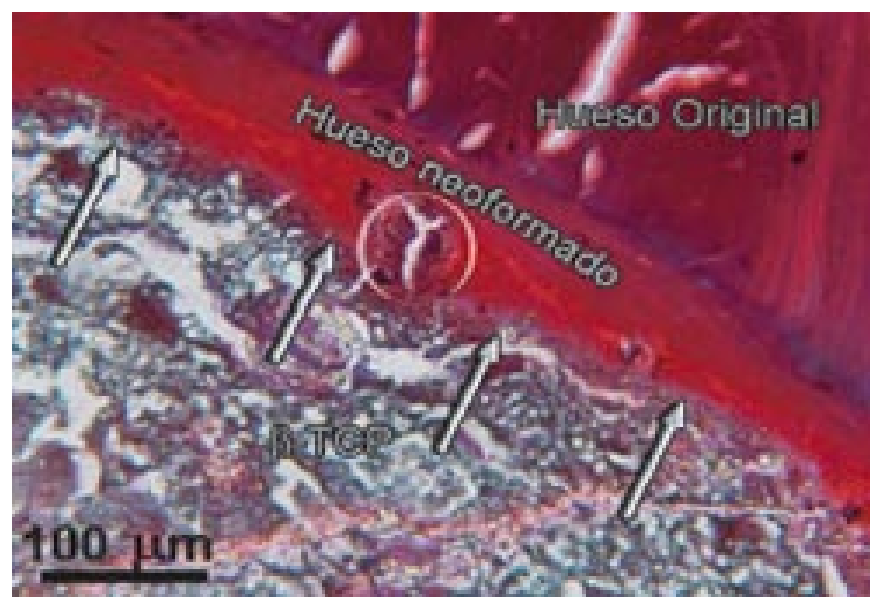

Fig. 7.- Fotografía de microscopía óptica de luz transmitida. Las flechas marcan la aposición directa de hueso neo-formado sobre la superficie del material tras 7 meses de implantación. En el interior de la marca circular se aprecia la inserción de una yema vascular.

que presentaba el hueso original. De acuerdo con lo observado se puede decir que hay una buena estabilidad inicial de la interfase. La determinación precisa de estos datos así como la evolución del índice contacto implante-hueso en cada uno de los materiales necesita la realización de un estudio histométrico que se realizará a posteriori. En ninguna de las preparaciones se observó desarrollo de tejido fibroso denso, de encapsulación o de rechazo agudo por parte del huésped. Tampoco se observó la presencia masiva de células inflamatorias ni de procesos agudos ni crónicos.

\section{CONCLUSIONES}

Se ha puesto a punto un método para la fabricación de $\beta$-TCP en grandes cantidades cumpliendo la norma de pureza ASTM F 1088-87 para el empleo de $\beta$-TCP a nivel quirúrgico. La pureza resultante determinada por DRX es $>99 \%$.

La síntesis que permite obtener un $\beta$-TCP de mayor pureza, en mayores cantidades, es la que se llevó a cabo con una velocidad de adición de $30 \mathrm{l} / \mathrm{min}$, un envejecimiento de 1 minuto, pH 10 y concentraciones de $1,11 \mathrm{M}$ y $0,74 \mathrm{M}$ para calcio y fosfatos respectivamente.

Se han estudiado distintas rutas de conformación, determinándose las condiciones óptimas de trabajo para cada una de ellas. Estos procesamientos optimizados permiten obtener piezas con formas geométricas diferentes y resistencias de compresión de hasta $200 \mathrm{MPa}$.

A falta de la realización de un estudio histométrico riguroso, el $\beta$-TCP presenta un buen comportamiento tras su implantación en hueso. Los componentes del material implantado son incorporados a la matriz intercelular del huésped, pudiendo considerarse, por tanto, como un auténtico andamio sobre el que se puede llevar a cabo el crecimiento de hueso nuevo (osteoconducción).

Parte de los procedimientos aquí expuestos fueron cedidos bajo contrato a la empresa Keramat S.L, y a día de hoy las piezas implantables de $\beta$-TCP, con Marcado C.E. se encuentran disponibles en el mercado sanitario bajo la marca comercial Keramedic ${ }^{\circledR}$.

\section{AGRADECIMIENTOS}

Los autores agradecen la financiación parcial de este trabajo a la Xunta de Galicia y al Ministerio de Educación y Ciencia (Proyectos PGIDT01TIN23901PR y MAT2002-03857 respectivamente).

\section{BIBLIOGRAFÍA}

1. F. H. Albee, Fundamentals in bone transplantation. Experiences in three thousand bone graft operations, J.A.M.A., 1923, 81:1429-1432, en Constanz, Brent. R.; Ison, Ira C; Fulmer, Mark T.; Poser, Robert D.; Smith, Susanne T.; VanWagoner, Michelle; Ross, John; Goldstein, Steven A.; Jupiter,Jesse B.; Rosenthal, Daniel I.; Science, 1995, 267, 1796-1799.

2. L.L. Hench, Bioceramics, J Am Ceram Soc, 1998, 81, 7, 1705-1733.

3. D. Stubbs, M. Deakin, P. Chapman-Sheath, J. Bruce, W. Debes, R.M. Gillies, W.R. Walsha, In vivo evaluation of resorbable bone graft substitutes in a rabbit tibial defect model, Biomaterials 2004, 25, 5037-5044.

4. R. Schnettler, J. P. Stahl, V. Alt, T. Pavlidis, E. Dingledein, S. Wenish, Calcium Phosphate-Based Bone Subtitutes, Eur J Trau ma, 2004,30, 219-29.

5. G. Daculsi, R.Z. LeGeros, D. Mitre, Cristal disolution of biological and ceramic apatites. Calciff Tissue Int., 1989, 45, 95-103.

6. Dental restorative cement pastes L. Chow, W. Brown.US Patent 4518430, 1983.

7. Driessens, F.C.M., Formation and Stability of Calcium Phosphates in relation to the Phase Composition of the Mineral Calcified Tissues en Bioceramics of Calcium Phosphate, Ed. de Groot, K., C.R.C. press, Boca Raton, Florida, 1990.

8. G. Daculsi, Biphasic calcium phosphate concept applied to artificial bone, implant coating and injectable bone substitute, Biomaterials, 1998, 19, 16, 1473-1478.

9. M. J. Yaszemski, R.G. Payne, W.C. Hayes, R. Langer, A. G. Mikos, Evolution Of Bone Transplantation: Molecular, Celular And Tissue Strategies To Engineer Human Bone, Biomaterials, 1996, 17, 2, 175-185.

10. M. Saito, H. Shimizu, M. Beppu, M. Takagi The role of btricalcium phosphate in vascularized periosteum, J Orthop Sci, 2000, 5 ,275-282.

11. K. Ohsawa, M. Neo, H. Matsuoka, H. Akiyama, H. Ito, H. Kohno, T. Nakamura, The expression of bone matrix protein mRNAs around betaTCP particles implanted into bone. J Biomed Mater Res, 2000, 52, 460-466.

12. K. Kurashina, H. Kurita, Q. Wu, A. Ohtsuka, H. Kobayashi, Ectopic osteogenesis with biphasic ceramics of hydroxyapatite and tricalcium phosphate in rabbits. Biomateriasls, 2002, 23, 2, 407-12.

13. R. Rohanizadeh, M. Trécant-Viana, G. Daculsi, Ultrastructural Study of Apatite Precipitation in Implanted Calcium Phosphate Ceramic: Inflluence of implantated site, Calcif Tissue Int, 1999, 64, 434-436

14. F. Guitian Rivera, R. Conde-Pumpido, C. Santos Expósito, A. Pazo Vazquez, J. Couceiro Follente, Biomateriales cerámicos: Síntesis y propiedades de hidroxiapatito y O-fosfato tricálcico, Bol. Soc. Esp. Ceram. V., 1990, 29 (4): 253- 257.

15. H.P. Klug, L.E. Alexander, X-Ray Diffraction Procedures (For Polychrystalline and Amorphous Materials), $2^{\text {nd }}$ Edition, 131-138, Wiley-Interscience publication, JohnWiley \& Sons, New York 1974.

16. N. Sarkar, G. K. Jr. Gremiger, Methylcellulose Polymers as Multifunctional Processing Aids in Ceramics, Ceramic Bulletin 1983, 62, (11) 1280-1288.

17. D.S. Metsger, M.R. Rieger, D.W. Foreman, Mechanical Propierties of Sintered Hydroxyapatite and Tricalcium Phosphate Ceramic, J.Mater. Sci: Mater in Med 10 (1999) 9-17.

18. M. Assad, P. Jarzem, M. A. Leroux, C. Coillard, A. V. Chernyshov, S. Charette, C-H. Rivard, Porous Titanium-Nickel for Intervertebral Fusion in a Sheep Model: Part 1. Histomorphometric and Radiological Analysis, J Biomed Mater Res Part B: Appl Biomater, 2003, 64B, 107-120.

Recibido: 14.02 .05

Aceptado: 28.08.05 